\title{
PREDICTING THE PERFORMANCE PARAMETERS OF CHISEL PLOW USING NEURAL NETWORK MODEL
}

\author{
Samy Marey ${ }^{1,2 *}$, Abdulwahed Aboukarima ${ }^{2,3}$, Yousef Almajhadi ${ }^{3}$
}

\author{
${ }^{1,2 *}$ Corresponding author. King Saud University - Sciences, Technology and Innovation Unit/ Riyadh, Saudi Arabia. \\ E-mail: samarey@ksu.edu.sa | ORCID ID: https://orcid.org/0000-0002-0261-2110
}

\section{KEYWORDS \\ backpropagation- learning algorithm, draft, fuel consumption, overall energy efficiency.}

\begin{abstract}
This study examines the capability of an artificial neural network (ANN) approach using a backpropagation-learning algorithm to predict performance parameters for a chisel plow at three field sites with differing soils. The draft force, effective field capacity (EFC), fuel consumption rate (FC), overall energy efficiency (OEE), and rate of plowed soil volume (SVR) were predicted at varying plowing speeds, plowing depths, soil moisture contents, soil bulk densities, soil texture indexes, and tractor powers. Collected field data was divided into a training set (for predicting the required parameters) and testing set (for model validation). For the ANN algorithm, the number of hidden layers, neurons, and transfer functions were varied to construct different ANN architectures, which were then verified using various statistical criteria, such as mean absolute error. The results showed that an ANN with one hidden layer and 15 neurons was ideal. The developed ANN model predicted the draft force, EFC, FC, OEE, and SVR of the chisel plow with a mean absolute error of $3.23 \mathrm{kN}, 0.80 \mathrm{hah}^{-1}, 3.04 \mathrm{Lh}^{-1}, 2.78 \%$ and $1.06 \mathrm{~m}^{3} \mathrm{~h}^{-1}$, respectively in the testing phase.
\end{abstract}

\section{INTRODUCTION}

The chisel plow is an agricultural tool extensively used for the initial soil working of primary tillage. Tillage is important in seedbed preparation, seed placement, the addition of nutrients and other items to the soil, and in the management of water and pest levels (Lobb et al., 2007). Selecting the ideal chisel plow can be difficult, as multiple operational variables and parameters must be considered (Santos \& de Queiroz, 2016). The quality of the chiseling process depended on the depth of cut and working speed (Ibrahim et al., 2019).

One variable that needs to be considered is energy consumption, given that fuel is a substantial expenditure in crop production operations. The fuel consumption of tractors during tillage varies extensively, but can be reduced by selecting the ideal combination of tractor size and operating parameters for the given soil type (McLaughlin et al., 2008). Predictions of fuel consumption rates in tractors and the energy consumption parameters of primary tillage equipment under local conditions are therefore essential selection criteria in purchasing decisions (Almaliki et al., 2016; Ranjbarian et al., 2017).

Performance parameters are used to determine energy and power requirements, and include draft, fuel consumption, wheel slip, drawbar power, tractive efficiency, plowed soil volume rate, and overall energy efficiency (OEE) (Kheiralla et al., 2004; Ibrahim et al., 2019). Field experiments to obtain these parameters are tedious and costly, and require expensive measuring devices. To reduce these costs, mathematical models have been developed instead.

Several studies have developed empirical mathematical models to predict chisel plow performance parameters, and to better understand and optimize mechanized agricultural systems. For example, empirical mathematical models can determine the draft requirements and fuel consumption of tillage equipment (Sahu \& Raheman, 2006). Such models have been used to develop software that can aid in the management and proper selection agricultural machines (Baio et al., 2013).

\footnotetext{
${ }^{2}$ Agricultural Engineering Research Institute-Agricultural Research Center/ Giza, Egypt.

${ }^{3}$ King Saud University-College of Food and Agriculture Sciences/ Riyadh, Saudi Arabia.
}

Area Editor: Murilo Aparecido Voltarelli

Received in: 9-16-2019

Accepted in: 8-13-2020 
Alternatively, soft computing techniques can also be used, such as the artificial neural network (ANN) approach. ANNs are nonlinear computer algorithms that model the behavior of complicated nonlinear processes (Jahirul et al., 2009) and can identify complex relationships in data (Cirak \& Demirtas, 2014). Numerous farm machinery researchers have used ANNs in recent years. When Parlak et al. (2006) tested the accuracy of an ANN method that used a backpropagation learning algorithm to predict the specific fuel consumption of a diesel engine at various injector timings; they found that the ANN results were consistent with the experimental results. Roul et al. (2009) evaluated an ANN model to predict the draft requirement of tillage implements in sandy clay loam soil. The developed model predicted the draft requirement of moldboard plow, cultivator and disk harrow with an error $<6.5 \%$ when compared to the measured draft values. An ANN model with six training algorithms was used by Ajdadi \& Abbaspour-Gilandeh (2011) to predict fuel consumption from Nebraska Tractor Test Lab data. They found that both ANN and stepwise regression models displayed similar determination coefficients $\left(\mathrm{R}^{2}=0.986\right.$ and $\mathrm{R}^{2}=0.973$, respectively). Borges et al. (2017) found no significant difference between ANN model values and experimental values when estimating tractor fuel consumption during soil preparation. They concluded that the ANN technique was adequately reliable and accurate in predicting tillage fuel consumption. Shafaei et al. (2018) also found that an ANN model could predict tractor fuel efficiency parameters during tillage. Abbaspour-Gilandeh et al. (2020) found that ANN model could predict the draft force of a rigid tine chisel cultivator. The draft force was predicted based on soil moisture content, the tillage depth, forward speed and soil cone index. The results indicated that the linear regression model had a much lower accuracy and correlation coefficient for predicting the draft force compared to the ANN model.

One of the main factors influencing energy consumption is OEE of the tractor (Kazemi et al., 2014). Many researchers believe that the correct combination of tractor and plow result in higher OEE values and decreased fuel consumption (Far et al., 2015). When analyzing the performance of tractor equipment, it is crucial to compare draft efficiency and specific fuel consumption (Bowers Jr, 1985). The OEE can be calculated by dividing the net energy used per area by the total energy available in the volume of fuel used per area, while OEE includes the load matching of tractor and plow (López-Vázquez et al., 2019). The normal range for OEE is $10-20 \%$, which can be used to check the validity of fuel consumption measurements (Bowers Jr, 1985). A tractorplow arrangement with an OEE below $10 \%$ points to poor load matching and/or low tractive efficiency. A value above $20 \%$ points to a good load match and/or high tractive efficiency. Although the effect of plowing depth and forward speed on OEE has not yet been completely modeled, OEE models can be used to develop an energy consumption database for tractor-plow combinations, which could be useful when making purchasing decisions (Shafaei et al., 2019).

The plowed soil volume rate is a critical parameter used to determine the field performance of plows (Bukhari et al., 1988). It is defined as the volume of soil disturbed per unit time during tillage, and is dependent upon plow depth and field capacity. To our knowledge, no study has been published that utilizes an ANN model to predict the plowed soil volume rate, and OEE of the chisel plow. Conventional models for predicting these objective parameters only changed one variable. Our use of an ANN model resolves this difficulty.

Therefore, the objective of our study was to assess the capability of an ANN approach using a backpropagation-learning algorithm to predict performance parameters for a chisel plow at three field sites with different soil texture. We focused our predictions on draft, fuel consumption rate, plowed soil volume rate, OEE, and effective field capacity based on tractor power, soil texture index, soil bulk density, soil moisture content, plowing speed and plowing depth.

\section{MATERIAL AND METHODS}

\section{Field Experiment}

Three different sites with varying soil textures were used to predict the performance of a chisel plow. The first experiments were conducted in the Abies region, Alexandria Governorate, Egypt (latitude: 31 ${ }^{\circ} 13^{\prime} 09.3 \mathrm{~N}$, longitude: $\left.29^{\circ} 58^{\prime} 34.6^{\prime \prime} \mathrm{E}\right)$ and had a silty clay loam soil texture (52\% sand, $18 \%$ silt, and $30 \%$ clay). The second site was located at El Gemmaiza Research Station, El Gharbia Governorate, Egypt (latitude: 3047' $19.8 \mathrm{~N}$, longitude: $31^{\circ} 07^{\prime} 31.8 \mathrm{E}$ ) and had a clay soil (15\% sand, $40.6 \%$ silt and $44.4 \%$ clay). The third site was at a research farm owned by the Rice Mechanization Center, Meet El Deeba, Kafer El Sheikh Governorate, Egypt (latitude: $31^{\circ} 066^{\prime} 59.3 \mathrm{~N}$, longitude: $30^{\circ} 51^{\prime} 17.6 \mathrm{E}$ ) and had a clay soil $(28.5 \%$ sand, $17.7 \%$ silt and $53.7 \%$ clay). The draft force, effective field capacity, fuel consumption, overall energy efficiency, and volume of the plowed soil were determined at different plowing speeds (obtained by changing tractor gears), plowing depths, and soil moisture contents, using different tractor powers. Table 1 shows the ranges of tractor power, plowing speed, plowing depth, soil moisture content, and soil bulk density at each experimental site. Soil samples were collected from five random locations at each site. Samples were collected from a 30-cm topsoil layer using a cylindrical core sampler and dried at $105{ }^{\circ} \mathrm{C}$ for $24 \mathrm{~h}$ in an electric oven to determine soil moisture content and bulk density. 
TABLE 1. Ranges of tractor power, plowing speed, plowing depth, soil bulk density, and soil moisture content in the experimental sites.

\begin{tabular}{|c|c|c|c|c|c|c|}
\hline Sites & $\mathrm{TP}(\mathrm{kW})$ & $\mathrm{PD}(\mathrm{cm})$ & $\mathrm{PS}\left(\mathrm{kmh}^{-1}\right)$ & $\mathrm{SM}(\% \mathrm{db})$ & $\mathrm{SD}\left(\mathrm{gcm}^{-3}\right)$ & $\mathrm{N}$ \\
\hline Abies & 67 & 14.0 & $2.5,3.8,4.8$ & 18.2 & 1.28 & 3 \\
\hline \multirow{2}{*}{ El-Gemmeza } & \multirow{2}{*}{82} & $10,12,14,15$ & $3.5,4.8,5.7$ & 18.2 & 1.40 & 12 \\
\hline & & $10,12,15$ & 4.8 & 18.2 & 1.40 & 3 \\
\hline \multirow{4}{*}{ Meet El Deeba } & \multirow{4}{*}{82} & $10,13,15,16$ & $2.5,3.4,4.8$ & 17.4 & 1.35 & 12 \\
\hline & & $10,14,17,18$ & $2.4,3.5,4.6,5.1$ & 17.6 & 1.30 & 12 \\
\hline & & $10,13,14,16$ & $2.5,3.2,5.1$ & 20.1 & 1.38 & 12 \\
\hline & & $9,11,14,16$ & $3.2,3.7,4.7,6.9$ & 19.8 & 1.36 & 16 \\
\hline
\end{tabular}

$\mathrm{TP}=$ tractor power, $\mathrm{PD}=$ plowing depth, $\mathrm{PS}=$ plowing speed, $\mathrm{SM}=$ soil moisture content, $\mathrm{SD}=$ soil bulk density $\mathrm{N}=$ no. of observations.

A locally-manufactured chisel plow (RAU, Behera Company) was used for all three experiments. The plow weighed $460 \mathrm{~kg}(4.51 \mathrm{kN})$ and had a width of $175 \mathrm{~cm}$. It had seven shanks distributed in two rows. At the second and third sites, the chisel plow was hitched to a Ford tractor model TW15 with a diesel engine of $110 \mathrm{~kW}$ at $2300 \mathrm{rpm}$. The auxiliary tractor was a Lamborghini tractor model 1106 with a diesel engine of $110 \mathrm{~kW}$ at $2500 \mathrm{rpm}$. A Kubota M1 tractor $(70 \mathrm{~kW})$ and Belarus $(67 \mathrm{~kW})$ were used as main and auxiliary tractors, respectively, at the first experimental site, where the draft was measured using a locally made strain gauge (Elashry et al., 1994; Younis et al., 2010) with a $10 \mathrm{kN}$ capacity that was connected between the two tractors using Arduino board arrangements (Hemeda et al., 2017). A fabricated locally made hydraulic pull meter (Mohamed et al., 2004) was used at the other two sites. The front tractor pulled the rear tractor with the chisel plow through the dynamometer at the desired plowing speeds and plowing depths. The draft was recorded by keeping the chisel plow in the lift position during the plowing pass.

The three-point linkage height lever of the tractor was set to random positions in order to obtain the different plowing depths. One pass of the chisel plow was used to test each depth at each location. Plowing depth was measured using a steel tape from the bottom of the furrow to the surface level of the soil. Ten measurements were taken for each run at different tilled profiles, and the average plowing depth was determined.

The required draft for each test was obtained by subtracting the draft force value while the plow was in the lift position from the draft force under the operating condition. The drawbar power (DBP, $\mathrm{kW}$ ) was calculated as

$$
D B P(k W)=\frac{D P \times S}{3.6}
$$

Where:

$$
\begin{aligned}
& \mathrm{DP} \text { - drawbar pull }(\mathrm{kN}) \text {, } \\
& \mathrm{S} \text { - plowing speed }\left(\mathrm{kmh}^{-1}\right) \text {. }
\end{aligned}
$$

A locally-manufactured fuel meter which is styled in Khadr (2004) was installed on the front tractor to measure the fuel consumption. The fuel consumption rate was determined in the unit of $\left(\mathrm{Lh}^{-1}\right)$ according to Khadr (2004).
The effective field capacity $\left(\mathrm{EFC}, \mathrm{hah}^{-1}\right)$ was calculated as the ratio of area covered by the tractor to the productive and nonproductive time according to the following formula:

$$
E F C=\frac{A}{T} \times 0.36
$$

Where:

$$
\begin{aligned}
& \text { A - plot area }\left(\mathrm{m}^{2}\right) \\
& \mathrm{T} \text { - total time required to finish the plot. }
\end{aligned}
$$

The OEE was calculated according to the equation reported by Bowers Jr (1985):

$$
\operatorname{OEE}(\%)=\frac{D B P}{P_{f}} \times 100
$$

Where:

$P_{f}$ - fuel equivalent power $(\mathrm{kW})$, and can be calculated as

$$
P_{f}(k W)=\frac{F C\left(L h^{-1}\right) \times H V\left(k^{k g} g^{-1}\right) \times \rho\left(\mathrm{kg} \mathrm{L}^{-1}\right)}{3600}=10.21 \times F C
$$

Where:

$\rho$ - density of diesel fuel (assumed to be 0.835 $\left.\mathrm{kgL}^{-1}\right)$;

HV - heating value of diesel fuel (assumed to be $44000 \mathrm{kJkg}^{-1}$ for diesel fuel according to Srivastava et al. (2006)),

FC - fuel consumption $\left(\mathrm{Lh}^{-1}\right)$.

The plowed soil volume rate $\left(\mathrm{SVR}, \mathrm{m}^{3} \mathrm{~h}^{-1}\right)$ is defined as the volume of disturbed soil during tilling per unit time. It was calculated according to Legahri et al. (2016) as

$$
\operatorname{SVR}\left(m^{3} h^{-1}\right)=E F C \times P D \times 100
$$

Where:

PD - plowing depth $(\mathrm{cm})$. 
To combine all soil fractions, a soil texture index (STI) using the Oskoui \& Harvey (1992) equation is as follows:

$$
S T I=\frac{\log \left(S^{c}+S a\right)}{100}
$$

Where:

$\mathrm{Sa}$ - percentage of sand content in the soil;

$\mathrm{S}$ - percentage of silt fraction in the soil,

$\mathrm{C}$ - percentage of clay fractions in the soil.

Oskoui \& Harvey (1992) showed that the STI reflects the effects of all three soil fractions as it produces unique numbers for every combination of sand, silt, and clay in soil.

\section{Building the ANN model}

Feedforward ANNs and error-backpropagation algorithms are common in the field of agricultural engineering (Shafaei et al., 2018). We selected a multilayer perceptron-based network for this study. The network was developed based on three layers (i.e., input, hidden, and output). Tractor power, soil texture index, initial soil bulk density, initial soil moisture content, plowing speed, and plowing depth were used as the input layers. The output layers included the draft, rate of the plowed soil volume, OEE, rate of fuel consumption, and effective field capacity. The advantage of the selected type of multi-layer perceptron is its ability to reduce prediction errors by modifying its biases and weights. This type of network is characterized by its use of many transfer functions. It has an input layer that is mapped to a hidden layer using an input transfer function, and a hidden layer that is mapped to the output layer using an output transfer function. The sigmoid transfer function is generally used in feedforward neural networks (Shafaei et al., 2018) and was accordingly used in this study. A flowchart describing the different steps used to develop the ANN model with Qnet 2000 is illustrated in Figure (1).

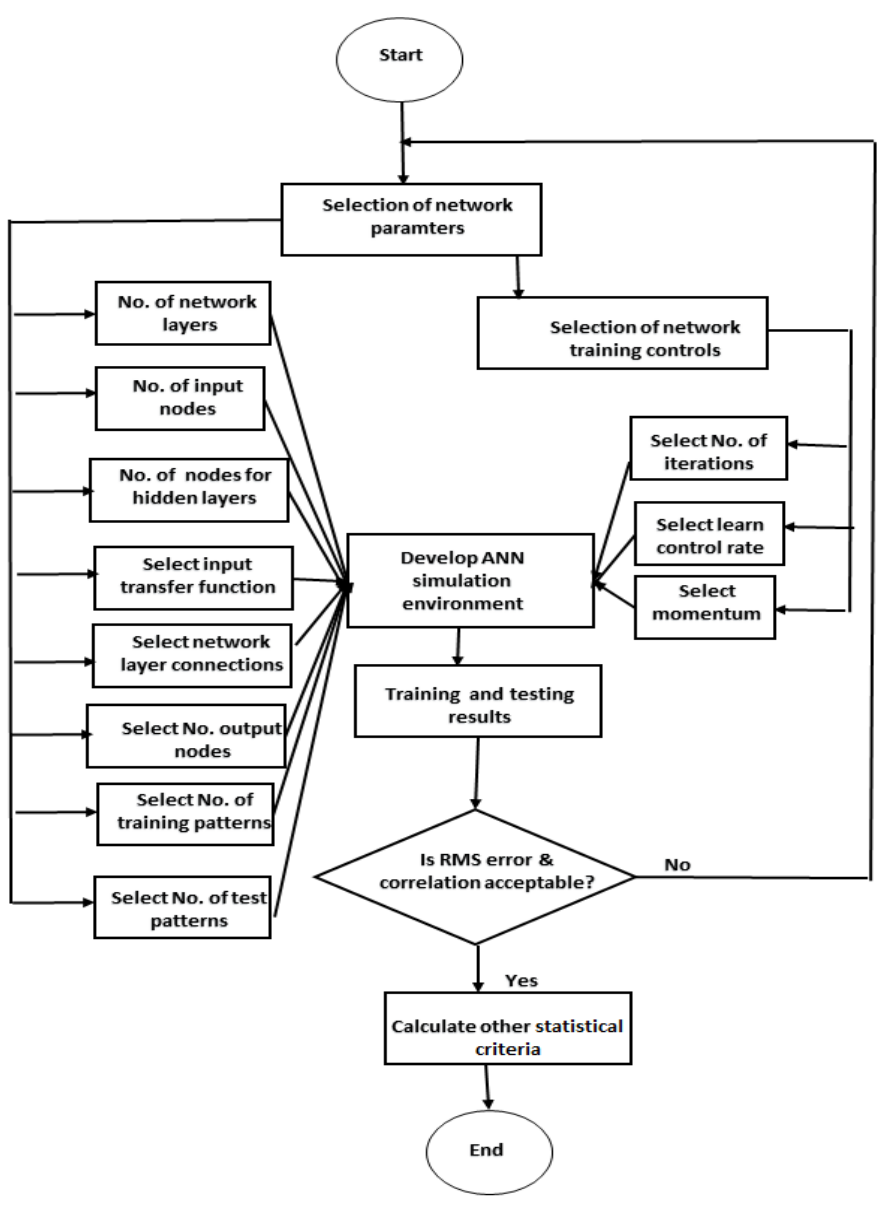

FIGURE 1. Steps for development of an ANN model using Qnet 2000 software.

The dataset obtained from the tillage experiments was completely processed to be suitable for the ANN simulation environment. Therefore, the input and output data were normalized to be in the range of $0.15-0.85$ by using the following equation (Vesta Services, 2000):

$$
X=\frac{\left(t-t_{\text {min }}\right)}{\left(t_{\text {max }}-t_{\text {min }}\right)} \times(0.85-0.15)+0.15
$$

Where:

$\mathrm{t}$ - the original values of input or output parameters;

$\mathrm{X}$ - the normalized value;

$t_{\max }$ - the maximum value of the input or output parameter,

$t_{\min }$ - the minimum value of the input or the output parameter. 
The Qnet 2000 software was directed to randomly select 15 observations as test data, which represent approximately $20 \%$ of the total dataset. Several architectures of ANN were built using a trial-and-error approach to achieve the form with the highest predictive capability. Different architecture parameters of the ANN (input and output transfer functions, the number of training iterations, and the number of neurons in the hidden layer) were tried through numerous simulation tests using Qnet 2000 (Vesta Services, 2000).
Figure (2) depicts the architecture of the ANN model used in this study, which was 6-15-5. The training mode used was a standard backpropagation algorithm with fully connected architectures, and used 45 observations as training patterns. The learning control started at number one, and the final learning rate was 0.022335 . The momentum was 0.8 , and the desired performance was terminated at iteration 28675 of 50000 . The hidden and output layers had a sigmoid transfer function and the training speed was $8720 \mathrm{~K}$.

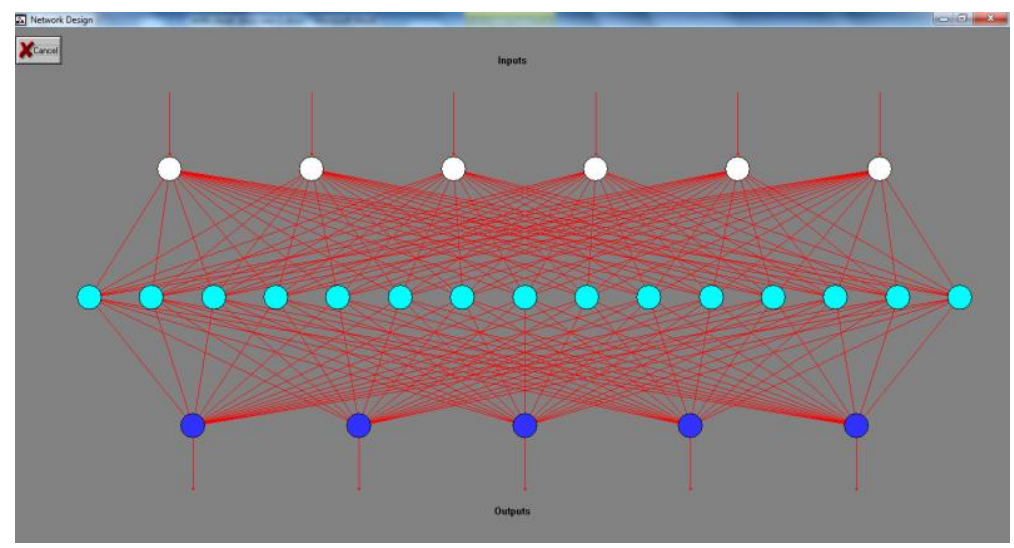

FIGURE 2. The architecture of the best ANN model used in this work was 6-15-5.

\section{Evaluation criteria for ANN model}

The coefficient of determination, mean absolute error (MAE), and root mean square error (RMSE) were used as statistical criteria for evaluating the accuracy of the predictive model. The error $e_{t}$ between the predicted and experimentally determined parameters were estimated as

$$
e_{t}=\mathrm{Y}_{t}-\hat{Y}_{t}
$$

Where:

$$
\begin{aligned}
& \dot{Y}_{t} \text { - the predicted value of the ANN model, } \\
& \mathrm{Y}_{\mathrm{t}} \text { - a value determined by the field experiments. }
\end{aligned}
$$

MAE is the sum of individual absolute errors normalized by the number of samples and was calculated as

$$
M A E=\frac{1}{N} \sum_{t=1}^{n}\left|\frac{e_{t}}{\mathrm{Y}_{\mathrm{t}}}\right|
$$

Where:

$$
\mathrm{N} \text { - number of observations. }
$$

RMSE is a modification of the mean absolute value, with the absolute value of an individual error term replaced with a square. It was determined using the following equation:

$$
R M S E=\sqrt{\frac{1}{N} \sum_{t=1}^{N} e_{t}^{2}}
$$

Both MAE and RMSE measure the difference between predicated and actual values. RMSE is more commonly used to measure the model's goodness-of-fit; however, it focuses more on large errors, owing to its square term. The adequacy of the ANN results generated for performance parameters of the chisel plow were evaluated according to the recommendations of Conceição \& Coelho (2003) using the confidence index (c), however, the confidence index (c) was calculated according to Camargo \& Sentelhas (1997) as

$$
c=r \times d
$$

Where:

$$
\begin{aligned}
& \mathrm{r} \text { - correlation coefficient } \\
& \mathrm{d} \text { - the index of agreement }
\end{aligned}
$$

The index of agreement (d) was calculated according to Willmott (1982):

$$
d=1-\left[\frac{\sum\left(\hat{Y}_{t}-Y_{t}\right)^{2}}{\sum\left(\left|\hat{Y}_{t}-\bar{Y}\right|+\left|Y_{t}-\bar{Y}\right|\right)^{2}}\right] \quad 0 \leq d \leq 1
$$

Where:

$$
\begin{aligned}
& \dot{Y}_{t} \text { - predicted value of the performance parameter; } \\
& \mathrm{Y}_{\mathrm{t}} \text { - the actual value of performance parameters; } \\
& \overline{\boldsymbol{Y}} \text { - mean value of the actual performance } \\
& \text { parameters, } \\
& \hat{\boldsymbol{Y}} \text { - mean value of the predicted performance } \\
& \text { parameters. }
\end{aligned}
$$


The confidence index (c) performance was evaluated according to a scale proposed by Camargo \& Sentelhas (1997) as shown in Table (2).

TABLE 2. Criteria for interpretation of the ANN model performance.

\begin{tabular}{cc}
\hline Value of "c" & Model performance \\
\hline$>0.85$ & Great \\
$0.76-0.85$ & Very good \\
$0.66-0.75$ & Good \\
$0.61-0.65$ & Median \\
$0.51-0.60$ & Affordable \\
$0.41-0.50$ & Bad \\
$>0.40$ & Terrible \\
\hline
\end{tabular}

\section{RESULTS AND DISCUSSION}

\section{Analysis of field data}

Table (3) shows the statistical values of the draft, effective field capacity, tractor fuel consumption, OEE, and plowed soil volume rate as they were measured and calculated from the three experimental sites. The average and median values of the draft, fuel consumption, and OEE were very similar, and therefore, the coefficient of variation was satisfactory.

The effective field capacity and plowed soil volume rate had large variations. However, this variation may be attributed to the fact that these parameters were calculated from parameters measured during the experiments. Since this study included a larger number of operating conditions, the higher deviations from these averages are justified.

TABLE 3. Statistical description of the performance parameters.

\begin{tabular}{llllll}
\hline & Draft $(\mathrm{kN})$ & $\mathrm{EFC}\left(\mathrm{hah}^{-1}\right)$ & $\mathrm{FC}\left(\mathrm{Lh}^{-1}\right)$ & $\mathrm{OEE}(\%)$ & $\mathrm{SVR}\left(\mathrm{m}^{3} \mathrm{~h}^{-1}\right)$ \\
\hline Minimum & 9.04 & 0.315 & 5.31 & 11.31 & 315.00 \\
Maximum & 15.48 & 0.907 & 11.96 & 20.82 & 1814.40 \\
Average & 12.41 & 0.514 & 8.62 & 15.10 & 783.42 \\
Median & 12.76 & 0.459 & 8.54 & 14.55 & 755.34 \\
Standard deviation & 1.22 & 0.151 & 1.57 & 2.60 & 306.77 \\
$\mathrm{CV}(\%)$ & 9.84 & 29.392 & 18.17 & 17.21 & 39.16 \\
\hline
\end{tabular}

$\mathrm{CV}=$ coefficient of variation.

The recorded values of the draft force at the three experimental sites $(9.04-15.48 \mathrm{kN})$ are similar to those reported in previous studies for clay soil under different operation and soil conditions (9.97-13.03 kN) (Al-Taee \& Al-Rajaboo, 2015; Ranjbarian et al. 2017). The fuel consumption rates for the different operating conditions are listed in Table 3 and ranged from 5.31 to $11.96 \mathrm{Lh}^{-1}$, with an average value of $8.62 \mathrm{Lh}^{-1}$. Meselhy (2014) compared the performance of different chisel plow types under various forward speeds in sandy clay loam soil. He found that the fuel consumption rate fluctuated between 9.2 and $11.1 \mathrm{Lh}^{-1}$, with a forward speed ranging from 3.5 to $7.5 \mathrm{kmh}^{-1}$. In a similar study conducted by Karparvarfard \& Rahmanian-Koushkaki (2015) in clay loam soil, the average fuel consumption rate was 14.03 $\mathrm{Lh}^{-1}$ at a soil moisture content of $8.4 \% \mathrm{db}$ (dry basis), a plowing depth of $20 \mathrm{~cm}$, and forward speed of $5 \mathrm{kmh}^{-1}$ while using a chisel plow with a width of $2.25 \mathrm{~m}$. Jebur \& Alsayyah (2017) used a chisel plow with a $2 \mathrm{~m}$ width in light soil under a plowing depth of $20 \mathrm{~cm}$, soil moisture content range of 10\%-11.96\%, and forward speed range of $5-5.2 \mathrm{kmh}^{-1}$. Under these conditions, they reported that the rate of fuel consumption ranged between 8.16 and 11.63 $\mathrm{Lh}^{-1}$. Generally, the results of the fuel consumption rate of our study coincided with the values reported in these previous studies.

The OEE ranged from $11.31 \%$ to $20.82 \%$, with an average value of $15.10 \%$ (Table 3 ). These results agree with the findings reported by Ranjbarian et al. (2017). In the study by López-Vázquez et al. (2019), it was found that OEE was quite low when using chisel plow (6.88\%). Similar results were found in other studies with OEE ranges from $11 \%$ to $20.08 \%$ for different tillage equipment
(Celik et al., 2007; Khadr, 2008). Bowers Jr (1985) stated that higher OEE indicates a good load match and/or a high tractive efficiency.

The plowed soil volume rate ranged from 315 to $1814.4 \mathrm{~m}^{3} \mathrm{~h}^{-1}$, with an average value of $783.42 \mathrm{~m}^{3} \mathrm{~h}^{-1}$ (Table 3). These values were similar to the values reported in previous research conducted under similar conditions (Ashour \& Safi, 2015; Muhsin, 2017). Other studies found similar results and reported that the volume of soil moved ranged from 1190 to $2310 \mathrm{~m}^{3} \mathrm{ha}^{-1}$, with an average of 1658 $\mathrm{m}^{3} \mathrm{ha}^{-1}$ for the chisel plow at an average plowing depth of $16.6 \mathrm{~cm}$ (López-Vázquez et al, 2019).

The effective field capacity ranged from 0.315 to $0.907 \mathrm{hah}^{-1}$ with an average value of $0.514 \mathrm{hah}^{-1}$ (Table 3). These results were similar to values obtained by other research (Meselhy, 2014) and are therefore considered acceptable.

\section{Performance of ANN model}

The draft force, effective field capacity, fuel consumption rate, OEE, and plowed soil volume rate performance parameters were modeled using ANN. Results showed that the ANN model with the 6-15-5 structure and standard backpropagation training algorithm performed well. The correlation coefficients during the training and testing stages were dramatically changed and improved with each iteration, with recorded values of 0.99 and 0.98 during the training and testing stages, respectively (data not shown). However, in ANN model for predicting the draft force of a rigid tine chisel cultivator with two hidden layers (24 and 26 neurons in the first and second layers, respectively with the use of the scaled conjugate gradient descent algorithm, AbbaspourGilandeh et al. (2020) attained coefficients of 
determination of $0.826004,0.767925$, and 0.788527 for the training, evaluation, and testing stages. In addition, the training and testing errors were sharply reduced by each iteration, with values of 0.024 and 0.06 during the training and testing stages, respectively (data not shown). The normalized actual data and the predicted data for the training and testing datasets is presented in Figure (3). The similarity between the predicted and actual values indicate that the ANN model was accurate in its prediction of all performance parameters.

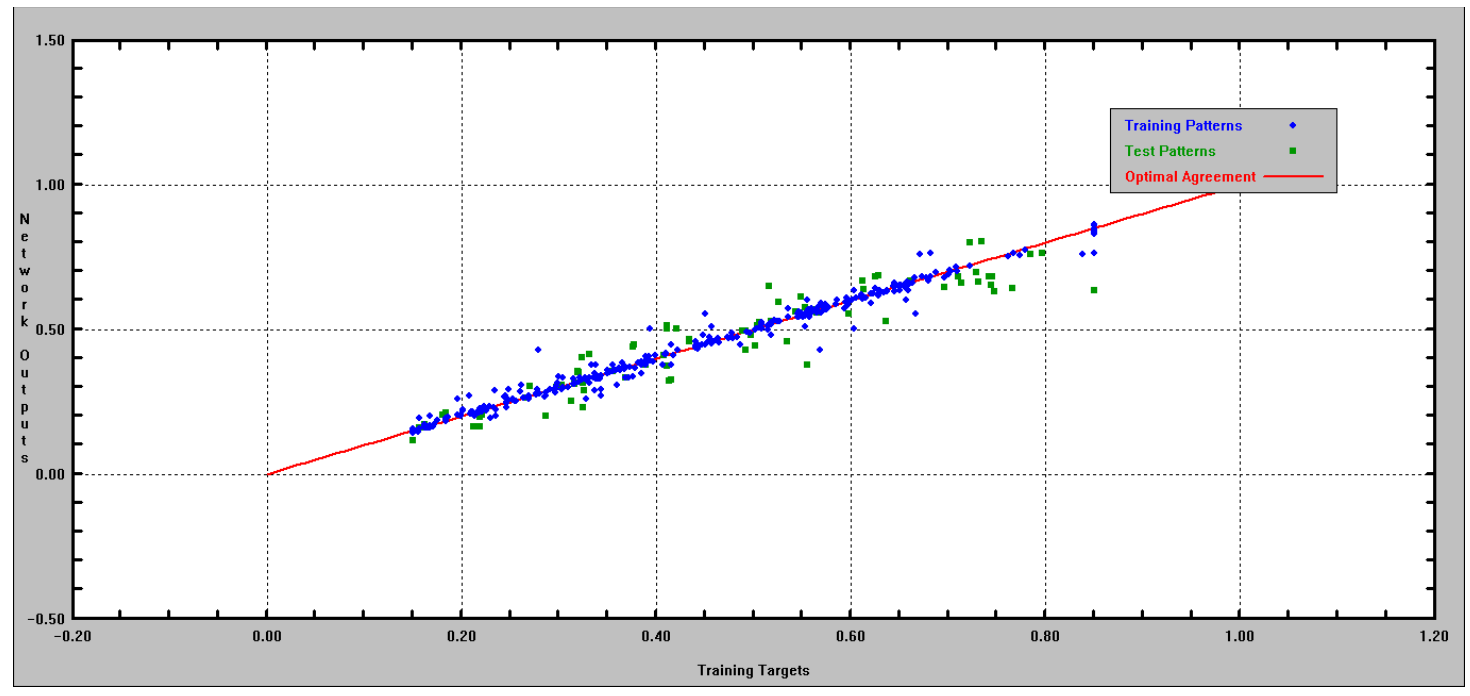

FIGURE 3. The scatter comparison of normalized targets versus net output.

Error criteria such as $\mathrm{R}^{2}$, RMSE, and MAE in the training and testing phases are given in Table 4. The coefficient of determination $\left(\mathrm{R}^{2}\right)$ was slightly low ( 0.86 and 0.8467 ) in the draft predictions compared to the other parameters respectively for the training and testing stages. This may be explained by existence of noise and fluctuation in the data, however, minimum value of draft was $9.04 \mathrm{kN}$ and maximum value of draft was $15.48 \mathrm{kN}$ as shown in Table (3). Moreover, $\mathrm{R}^{2}$ does not disclose information about the causation relationship between the independent and dependent variables and it does not indicate the correctness of the regression model, however, it provides information about the strength and direction of a relationship between two continuous variables (Schneider et al., 2010). The $\mathrm{R}^{2}$ values for effective field capacity (0.99 and 0.9988), rate of fuel consumption (0.99 and 0.9644), OEE (0.99 and $0.9537)$, and plowed soil volume rate $(0.99$ and 0.999$)$, are also listed in Table 4, respectively for the training and testing stages. Confidence index (c) values, the correlation coefficient (r), the index of agreement (d), and the model performance criteria for the testing dataset are presented in Table 5. The confidence index values for the draft force and effective field capacity were 0.71 and 0.66 , respectively. According to Camargo \& Sentelhas (1997), draft force and effective field capacity predictions using ANN are acceptable. For the other parameters, the confidence index was higher than 0.85 , and therefore, the prediction of these parameters using the ANN model was excellent.

TABLE 4. Summary of statistical criteria to evaluate the ANN model efficiency during training and testing stages.

\begin{tabular}{lllllll}
\hline & \multicolumn{2}{l}{ Testing dataset } & \multicolumn{3}{l}{ Training dataset } \\
\cline { 2 - 7 } & Rarameters & MAE & RMSE & R & MAE & RMSE \\
\hline Draft $(\mathrm{kN})$ & 0.8467 & 3.23 & 0.57 & 0.86 & 2.15 & 0.44 \\
EFC $\left(\mathrm{hah}^{-1}\right)$ & 0.9988 & 0.80 & 0.005 & 0.99 & 0.61 & 0.004 \\
FC $\left(\mathrm{Lh}^{-1}\right)$ & 0.9644 & 3.04 & 0.32 & 0.99 & 1.32 & 0.16 \\
OEE $(\%)$ & 0.9537 & 2.78 & 0.62 & 0.99 & 1.05 & 0.23 \\
SVR $\left(\mathrm{m}^{3} \mathrm{~h}^{-1}\right)$ & 0.999 & 1.06 & 8.44 & 0.99 & 0.85 & 8.26 \\
N & 15 & & & 55 & & \\
\hline
\end{tabular}

TABLE 5. Values of confidence index (c), correlation coefficient (d), index of agreement (r), and model performance criteria for testing dataset.

\begin{tabular}{lllll}
\hline Parameters & Model performance & "c" & "d" & "r" \\
\hline Draft force $(\mathrm{kN})$ & Good & 0.71 & 0.77 & 0.92 \\
EFC $\left(\mathrm{hah}^{-1}\right)$ & Good & 0.66 & 0.66 & 0.99 \\
FC $\left(\mathrm{Lh}^{-1}\right)$ & Great & 0.90 & 0.92 & 0.98 \\
OEE $(\%)$ & Great & 0.92 & 0.94 & 0.98 \\
SVR $\left(\mathrm{m}^{3} \mathrm{~h}^{-1}\right)$ & Great & 0.99 & 0.99 & 0.99 \\
\hline
\end{tabular}


Figure 4 to Figure 8 show the relationships and coefficients of determination between the actual and predicted values of draft force, effective field capacity, fuel consumption, overall energy efficiency, and plowed soil volume rate, respectively, using the ANN model during the testing phase. It can be observed that the points during the testing process were not uniformly scattered around the regression lines due to existence of noise and fluctuation in the data. However, measures of association provide an initial impression of the extent of statistical dependence between variables (Schneider et al., 2010). The values of $R^{2}$ show the satisfactory performance of the established ANN model.

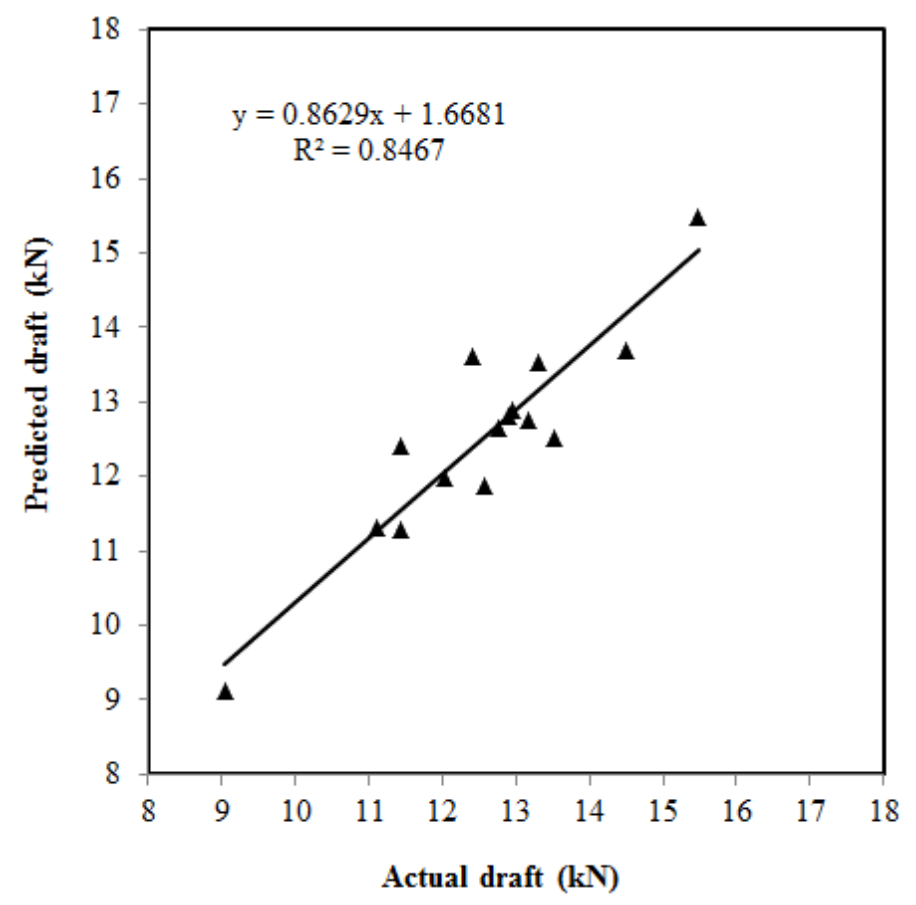

FIGURE 4. Relationship between the actual and ANN model predicted draft.

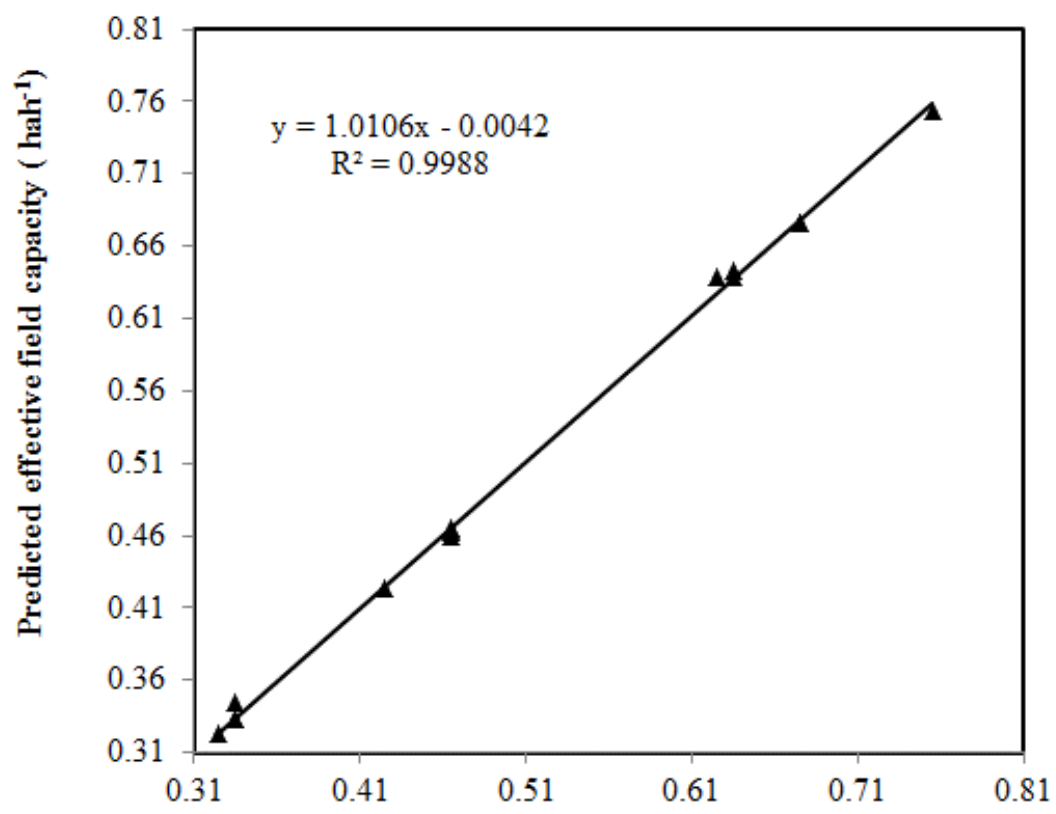

Actual effective field capacity $\left(\mathrm{hah}^{-1}\right)$

FIGURE 5. Relationship between the actual and ANN-model-predicted effective field capacity. 


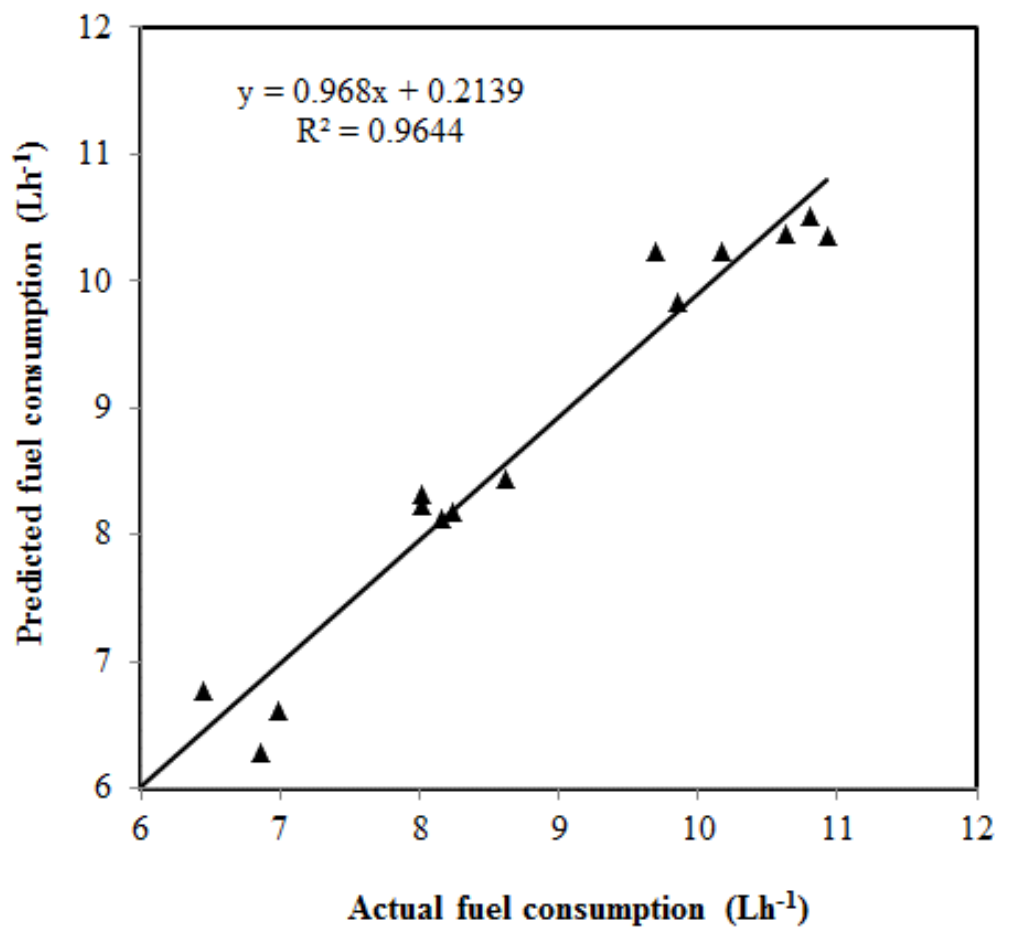

FIGURE 6. Relationship between the actual and ANN-model-predicted rate of fuel consumption.

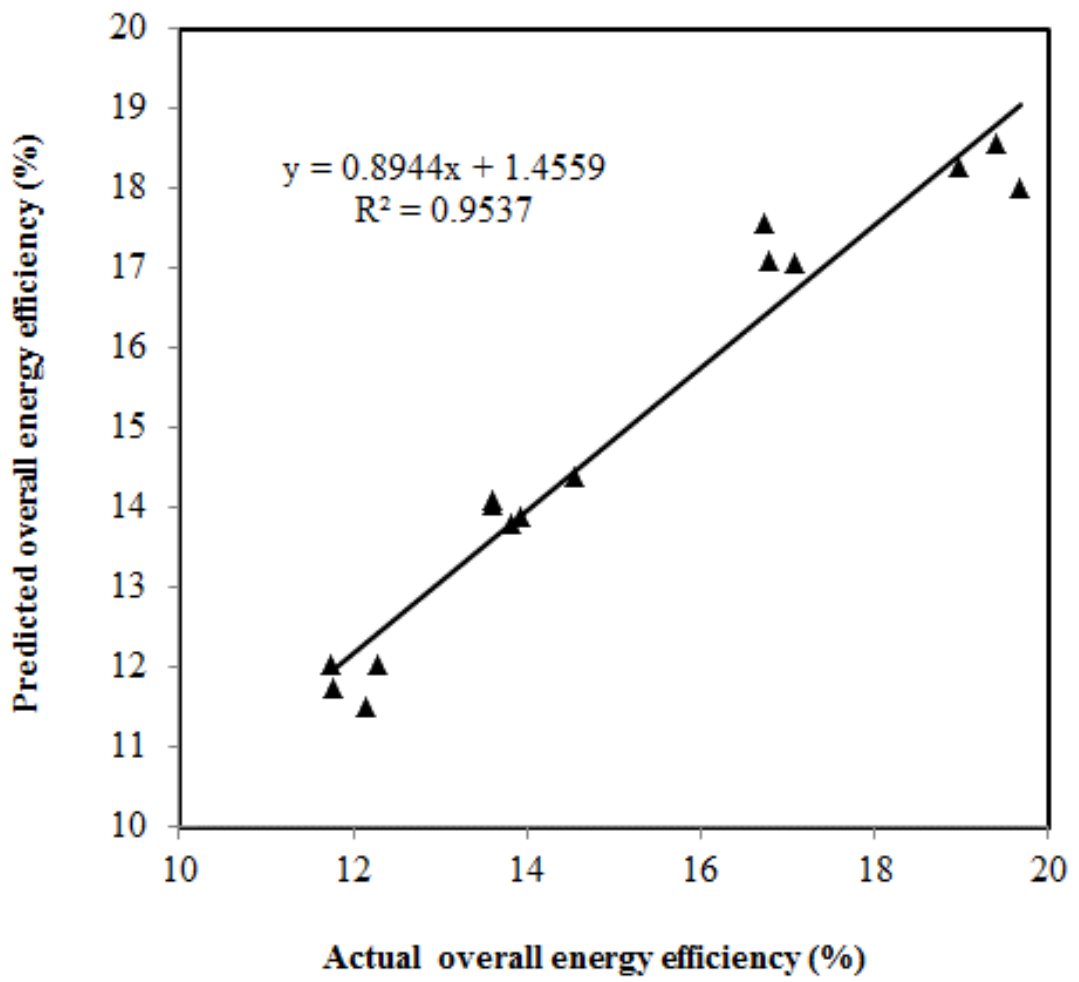

FIGURE 7. Relationship between the actual and ANN-model-predicted overall energy efficiency. 


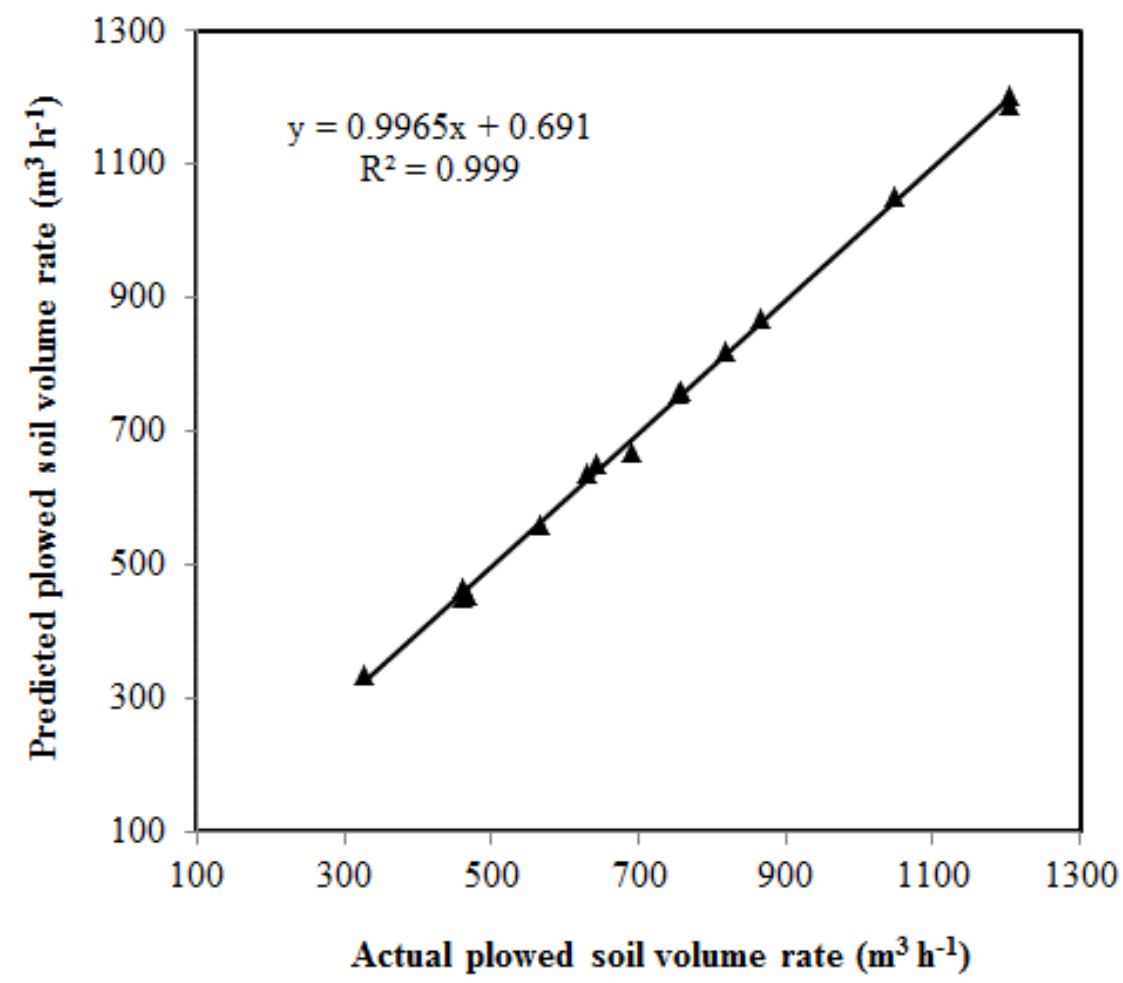

FIGURE 8. Relationship between the actual and ANN-model-predicted rate of plowed soil volume.

\section{Determining the effect of inputs on outputs (inputs interrogator)}

The Qnet algorithm computed the percentage of contribution, which indicates how the change in each input affects the output prediction. The contribution percentage of the six input variables to their outputs was calculated using the developed ANN model, and the results are illustrated in Figure (9) for draft force, effective field capacity, rate of fuel consumption, overall energy efficiency, and rate of plowed soil volume. This figure can be used to determine the relative contributions and importance of each parameter included in the study. It is clear from Figure (9) that the contribution of the tractor power on draft prediction was the highest as compared to the other parameters, with a contribution percentage of $25.72 \%$. This phenomenon may be attributed to the use of tractors with high power enables the tractor to use its full power at low speed closer to the practical speed (AbdelMageed, 1994), who pointed out that the 4WD tractor delivered more power ( 9 to $20.5 \%$ ) and more output rate (4 to $18 \%$ ) than 2WD tractor. The maximum tractive efficiencies obtained were 82.9 and $76.6 \%$ for the 4WD and 2WD tractors, respectively. Also, the contribution of the tractor power on draft prediction was higher than the other parameters may be attributed to the high static load on the rear tires of the tractor increases the tractive force due to the weight transfer according to interpretations of Leite et al. (2011).

The plowing speed had the highest contribution to the rate of fuel consumption, effective field capacity, OEE and plowed soil volume rate. The corresponding contribution percentages were $47.45 \%, 87.48 \%, 62.44 \%$ and $50.58 \%$, respectively. In the study by Shafaei et al. (2019), they inferred that a plowing speed increase from 2 to $6 \mathrm{kmh}^{-1}(200 \%)$ led to a significant OEE rise (approximately 112\%). From a farm machinery management point of view, this means that by selecting the best forward speed, a higher OEE can be attained. Given the varying degrees of significance of different parameters on OEE, agricultural engineers should focus their improvements on significantly important parameters in regards to OEE. Accordingly, the agricultural engineers can establish and pay attention to the parameters that dominate the state of the output, and ignore those having small contributions. 


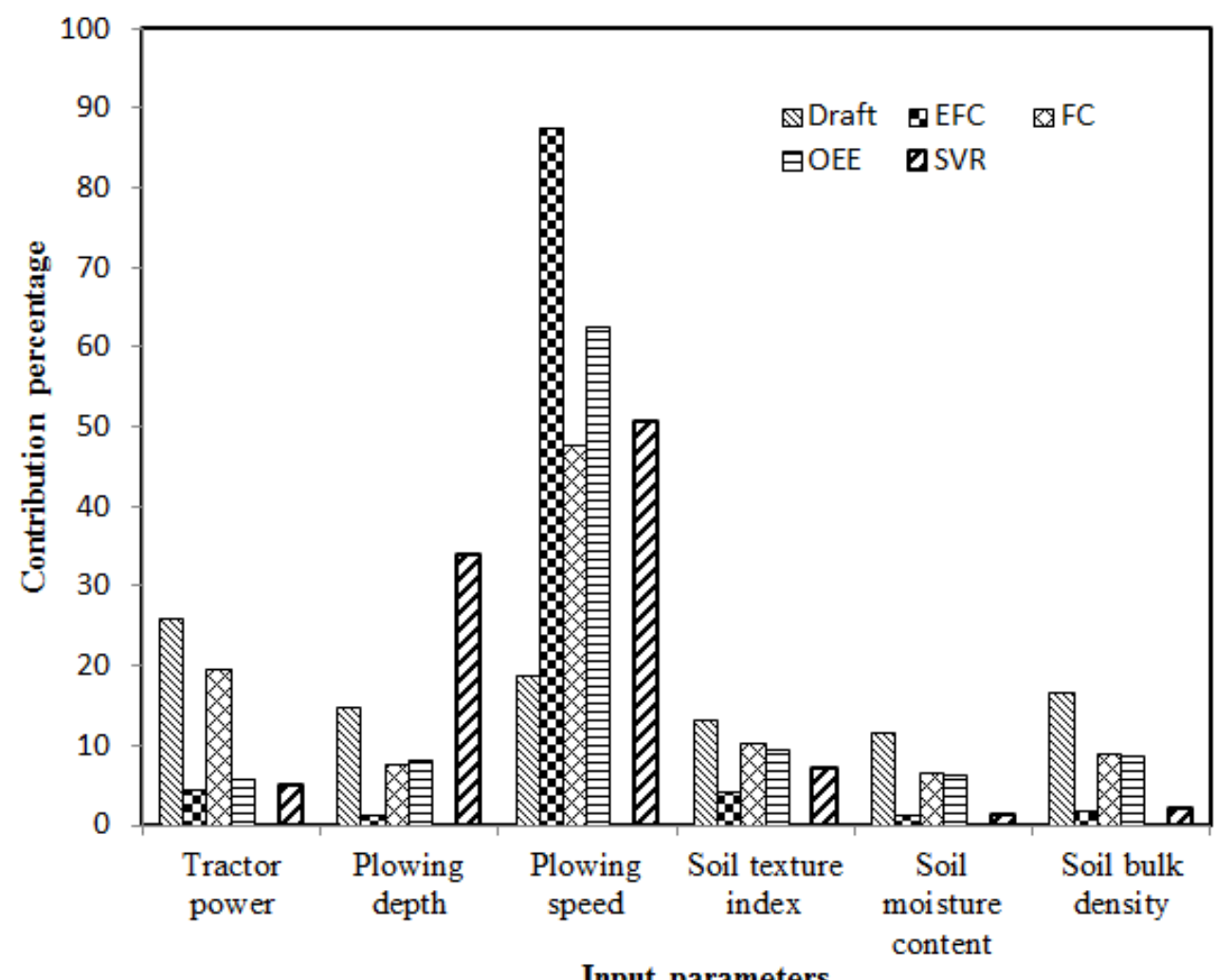

FIGURE 9. Contribution percentage of 6 independent variables used in the ANN model for prediction of draft, effective field capacity (EFC), rate of fuel consumption (FC), overall energy efficiency (OEE), and rate of plowed soil volume (SVR).

\section{CONCLUSIONS}

A backpropagation neural network model with a 615-5 configuration (number of input, hidden and output layers nodes) was developed to predict the draft force, effective field capacity, rate of fuel consumption, overall energy efficiency, and rate of plowed soil volume of the chisel plow. The input parameters of the ANN were the plowing speed, plowing depth, soil moisture content, soil bulk density, soil texture index and tractor power. The determination coefficients of the ANN model for the above mentioned parameters in validation phase were $0.8467,0.9988,0.9644,0.9537$ and 0.999 , respectively. Therefore, the developed model is useful for predicting the performance parameters of the chisel plow. It is proposed that our ANN model was reliable and accurate, thus justifying its application for the management of chisel plow operations.

\section{ACKNOWLEDGMENTS}

The authors offer sincere thanks and appreciation to the Deanship of Scientific Research and RSSU, King Saud University, Saudi Arabia, for supporting this research effort.

\section{REFERENCES}

Abbaspour-Gilandeh Y, Fazeli M, Roshanianfard A, Hernández-Hernández, Gallardo-Bernal I, HernándezHernández JL (2020) Prediction of draft force of a chisel cultivator using artificial neural networks and its comparison with regression model.

Agronomy 10:451. DOI:

https://doi.org/10.3390/agronomy10040451
Abdel-Mageed RN (1994) A field comparison on the performance of a two and four wheel drive tractor in chisel plowing. Misr Journal of Agricultural Engineering 11(3):636-654.

Ajdadi F, Abbaspour-Gilandeh Y (2011) Artificial neural network and stepwise multiple range regression methods for prediction of tractor fuel consumption. Measurement 44(10):2104-2111. DOI:

https://doi.org/10.1016/j.measurement.2011.08.006

Almaliki S, Alimardani R, Omid M (2016) Prognostication of fuel consumption for Massey Ferguson tractor (MF 285) by artificial neural network based modeling approach. The National Congress on Biosystems Engineering (Agricultural Machinery) and Mechanization 1:1-14. Mashhad: Iran.

Al-Taee MEA, Al-Rajaboo SAJ (2015) Effect of chisel plow shanks shape on power requirements of tractor. AL Rafdain Engineering Journal 6:17-26 (Abstract in English).

Ashour D, Safi H (2015) The effect of chisel plow type, operating depth and forward speed on the energy requirement and some filed performance indicators in silty clay soil. Journal of Basrah Researches- Sciences 41:1-11.

Baio F, Rodrigues A, Santos G, Silva S (2013)

Mathematical modeling to select mechanized agricultural systems by the lowest operational cost. Engenharia Agrícola 33:402-410. DOI:

http://dx.doi.org/10.1590/S0100-69162013000200018 
Borges P, Mendoza ZMSH, Maia JCS, Bianchini A, Fernándes HC (2017) Estimation of fuel consumption in agricultural mechanized operations using artificial neural networks. Engenharia Agrícola 37: 136-147. DOI: http://dx.doi.org/10.1590/1809-4430eng.agric.v37n1p136-147/2017.

Bowers Jr CG (1985) Southeastern tillage energy data and recommended reporting. Transactions of the ASAE 28(3):731-737. DOI:

http://dx.doi.org/10.13031/2013.32329

Bukhari S, Bhutto M, Baloch J, Bhutto A, Mmirain N (1988) Performance of selected tillage implements. Journal of Agricultural Mechanization in Asia, Africa and Latin America (AMA) 19: 9-14.

Camargo AP, Sentelhas PC (1997) Evaluation of the performance of different methods of estimation of potential evapotranspiration in the state of São Paulo. Revista Brasileira de Agrometeorologia 5(1):89-97.

Celik A, Boydas MG, Turgut N (2007) Comparison of the energy requirements of an experimental plow, a moldboard plow and a disk plow. Philippine Agricultural Scientist 90(2):173-178.

Cirak B, Demirtas S (2014) An application of artificial neural network for predicting engine torque in a biodiesel engine. American Journal of Energy Research 2(4):74-80. DOI: http://dx.doi.org/10.12691/ajer-2-4-1.

Conceição M, Coelho R (2003) Simulating wind effect on microsprinkler water distribution. Scientia Agricola 60(2): 205-209. DOI: http://dx.doi.org/10.1590/S010390162003000200001.

Elashry ER, Bassuni AM, Sayed Ahmed AA, Ahmed KA (1994) An instrumentation system for measuring the tractor performance. Misr Journal of Agricultural Engineering 11(4):968-987.

Far AS, Kazemi N, Rahnama M, Nejad MG (2015) Simultaneous comparison of the effects of shaft load and shaft positions on tractor OEE in two soil conditions (cultivated and uncultivated). International Journal of Farming and Allied Sciences 4: 215-221.

Hemeda S, Aboukarima A, Minyawi M (2017) Developing a logging unit for measuring and recording power data using Arduino board. Misr Journal of Agricultural Engineering 34:2053-2072.

Ibrahim IE, Ji C, He R, Ding Q, El Sheikh AH, Soomro SA, Idris SI (2019) Quantifying performance of chisel plow in heavy clay soil of Gezira scheme - Sudan. International Agricultural Engineering Journal 28(1):7987. DOI: http://114.255.9.31/iaej/EN/Y2019/V28/I1/9

Jahirul M, Rahman S, Masjuki H, Kalam M, Rashid M (2009) Application of artificial neural networks (ANN) for prediction the performance of a dual fuel internal combustion engine. Journal HKIE Transactions 16:14-20. DOI: https://doi.org/10.1080/1023697X.2009.10668146.

Jebur H, Alsayyah Y (2017) Study of the soil moisture content and the tractor speed on the performance efficiency of the machinery unit. IOSR Journal of Agriculture and Veterinary Science (IOSR-JAVS) 10:6570. DOI: http://dx.doi.org/10.9790/2380-1005016570.
Karparvarfard S, Rahmanian-Koushkaki H (2015)

Development of a fuel consumption equation: Test case for a tractor chisel-ploughing in a clay loam soil. Biosystems Engineering 130:23-33. DOI: https://doi.org/10.1016/j.biosystemseng.2014.11.015

Kazemi N, Almassi M, Bahrami H, Shaykhdavoodi M, Mesgarbashi M (2014) Analysis of factors affecting the management of overall energy efficiency of tractorimplement by real-time performance monitoring. Journal of Agricultural Machinery 4:214-225.

Khadr KhAA (2004) Energy requirements for some seedbed preparation implement under Egyptian conditions. Annual Conference of the "Misr Society of Agricultural Engineering”. p481-491.

Khadr KhAA (2008) Effect of some primary tillage implement on soil pulverization and specific energy. Misr Journal of Agricultural Engineering 25:731-745.

Kheiralla A, Yahya A, Zohadie M, Ishak W (2004) Modelling of power and energy requirements for tillage implements operating in Serdang sandy clay loam. Malaysia, Soil and Tillage Research 78(1):21-34. DOI: https://doi.org/10.1016/j.still.2003.12.011.

Legahri N, Zehri Q, Shah A, Tagar A, Leghari R, Mangan $\mathrm{T}$ (2016) Comparison of shallow and deep tillage practices at different soil moisture content levels under climatic conditions of Sindh. Science International 28:2661-2666.

Leite F, dos Santos JEG, Lanças KP, JúniorJBL (2011) Evaluation of tractive performance of four agricultural tractors in laterally inclined terrain. Engenharia Agrícola 31(5):923-929. https://doi.org/10.1590/S010069162011000500010

Lobb DA, Huffman E, Reicosky DC (2007) Importance of information on tillage practices in the modelling of environmental processes and in the use of environmental indicators. Journal of Environmental

Management 82 (3):377-387.

https://doi.org/10.1016/j.jenvman.2006.04.019.

López-Vázquez A, Cadena-Zapata M, Campos-Magaña S, Zermeño-Gonzalez A, Mendez-Dorado Mario (2019) Comparison of energy used and effects on bulk density and yield by tillage systems in a semiarid condition of Mexico. Agronomy 9(4):189. DOI:

http://dx.doi.org/10.3390/agronomy9040189.

McLaughlin N, Drury C, Reynolds W, Yang X, Li Y, Welacky T, Stewart G (2008) Energy inputs for conservation and conventional primary tillage implements in a clay loam soil. Transactions of the ASABE 51: 11531163. DOI: http://dx.doi.org/10.13031/2013.25231

Meselhy A (2014) Design and performance evaluation of circular chisel plow in calcareous soil. International Journal of Emerging Technology and Advanced Engineering 4(11):1-8.

Mohamed AA, Bahnasy AF, Elgwady AA (2004) Design and calibration of a device to measure the pulling force of agricultural trailed implements. Misr Journal of Agricultural Engineering 21(2):532-521. 
Muhsin S (2017) Determination of energy requirements, plowed soil volume rate and soil pulverization ratio of chisel plow under various operating conditions. Basrah Journal of Agricultural Sciences 30:73-84.

Oskoui K, Harvey SJ (1992) Predicting cone index from soil physical properties and organic matter content. Paper American Society of Agricultural Engineers (92-1056):16.

Parlak A, Islamoglu Y, Yasar H, Egrisogut A (2006) Application of artificial neural network to predict specific fuel consumption and exhaust temperature for a diesel engine. Applied Thermal Engineering 26(8-9):824-828. DOI: https://doi.org/10.1016/j.applthermaleng.2005.10.006

Ranjbarian S, Askari M, Jannatkhah J (2017) Performance of tractor and tillage implements in clay soil. Journal of the Saudi Society of Agricultural Sciences 16(2):154-162. DOI: https://doi.org/10.1016/j.jssas.2015.05.003

Roul A, Raheman K, Pansare H, Machavaram R (2009) Predicting the draught requirement of tillage implements in sandy clay loam soil using an artificial neural network. Biosystems Engineering 104(4): 476-485. DOI: https://doi.org/10.1016/j.biosystemseng.2009.09.004

Sahu R, Raheman H (2006) Draught prediction of agricultural implements using reference tillage tools in sandy clay loam soil. Biosystems Engineering 94(2):275-284. DOI: https://doi.org/10.1016/j.biosystemseng.2006.01.015.

Santos FL, de Queiroz DM (2016) Simtrac-an application for simulation of traction efficiency of agricultural tractors with front wheel assist. Acta Scientiarum: Technology 38(4):423-430. DOI:

https://doi.org/10.4025/actascitechnol.v38i4.29218
Schneider A, Hommel G, Blettner M (2010) Linear regression analysis: Part 14 of a series on evaluation of scientific publications. Deutsches Ärzteblatt International 107(44):776-782.

DOI: https://doi.org/10.3238/arztebl.2010.0776

Shafaei S, Loghavi M, Kamgar S (2018) On the neurocomputing based intelligent simulation of tractor fuel efficiency parameters. Information Processing in Agriculture 5(2):205-223. DOI: https://doi.org/10.1016/j.inpa.2018.02.003.

Shafaei S, Loghavi M, Kamgar S (2019) Prognostication of energy indices of tractor-implement utilizing soft computing techniques. Information Processing in Agriculture 6(1):132-149. DOI: https://doi.org/10.1016/j.inpa.2018.08.001.

Srivastava AK, Goering CE, Rohrbach RP, Buckmaster DR (2006) Engineering Principles of Agricultural Machines. St. Joseph, 2 ed.

Vesta Services (2000) Qnet2000 Shareware. Winnetka, Vesta Services.

Willmott C (1982) Some comments on the evaluation of model performance. Bulletin American Meteorological Society 63(11):1309-1313. DOI: https://doi.org/10.1175/15200477(1982)063<1309:SCOTEO>2.0.CO;2

Younis SM, Elsaid RE, Bahnasy AF, Elsybaee IM (2010) Development a local system for measuring tractors performance. Misr Journal of Agricultural Engineering 27(1):34-53. 